\title{
Opportunities for change in the quantity and fatty-acid composition of carcass and milk fats
}

\author{
J. L. Jollans \\ M.A., A.I.C.T.A., M.I.Biol. \\ Centre for Agricultural Strategy, University of Reading, 2 Earley Gate, Reading RG6 $2 A U$
}

\begin{abstract}
Summary
Reduction of the amount of fat in carcasses has been in process for many years and will continue in response to consumer demand. With milk and dairy products, however, the demand for fat continues and available technology will only be used if the market changes.

Some increase of the polyunsaturated : saturated ratio (P/S) of carcass fat will automatically accompany reduction in quantity of fat, particularly with pigs. Further change is technically possible but might bring consumer resistance and shelf-life problems. With milk fat, the $P / S$ ratio could be increased by the feeding of protected, polyunsaturated oils although such an expensive approach could be avoided by changing the laws on dairy product nomenclature.
\end{abstract}

\section{Introduction}

There are few scientific problems in reducing, or increasing, the quantity of fat in meat and milk or in products derived from them. Two main qualifications limit the extent to which change is being, or could be made in commercial practice: Little happens until the consumer demands change and is prepared to pay for it; all change takes time, especially where genetic selection is involved.

Changing the proportions of the fatty-acids, in such a way as significantly to affect the ratio of polyunsaturated : saturated fatty acids $(P / S)$ in human diets, is more difficult.

\section{Quantity of carcass fat}

For many years, consumers of meat have been demanding a decrease in the proportion of fat to lean. Figure 1 illustrates the general pattern of bone, lean and fat formation resulting from a feeding regime which is generous in relation to genetic potential for growth. Whilst the rate of lean deposition is maximal, there is little formation of fat but when lean deposition slows, from about the time of puberty, surplus feed energy is stored as fat in increasing proportions.

Two methods arise of controlling the amount of fat in meat: Slaughter early, before the main period of fat deposition commences. Commercial examples are continental veal, spring lamb and the London porker. However, since the cost per $\mathrm{kg}$ of producing a newborn animal is high compared to the cost of later growth, early slaughter results in an expensive product. Limit feed intake in the later stages of growth. The Wiltshire bacon pig is a good example. However, if severe feed restriction is needed, the growing period is lengthened and this also results in an increase of production costs.

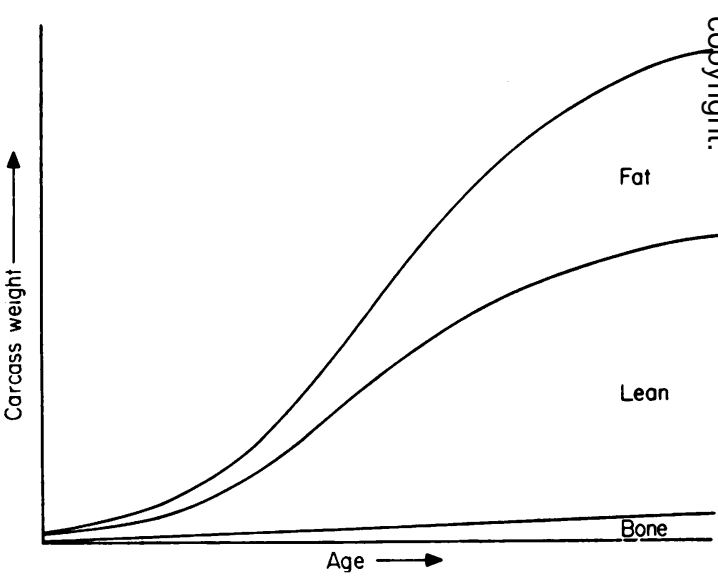

Fig. 1. Diagrammatic representation of bone, lean and fat development in the growing animal.

A third method, familiar to all meat consumers, is to remove the surplus fat and discard it. Whilst achieving the objective of reducing the fat content of the meat, as consumed, this method is wasteful. Consequently, when surplus fat is trimmed in the abattoir or the butcher's shop, every effort is made to disopose of that fat, at a profit, by incorporating it in sausages and pies. Indeed much research effort is directed to increasing the fat-holding capacity of such products and demand has been stimulated to such an extent that, when animals from U.K. farms are too lean to trim, fat may be imported for sausage and pie making. 


\section{Genetic change}

There is considerable variation between animals in their inherited capacity for fat deposition and estimates of the heritability $\left(h^{2}\right)$ of this character are usually in the range of $0 \cdot 3$ to $0 \cdot 5$. Such levels are adequate for commercial breeding programmes, especially since the development of methods of measuring on the live animal (e.g. ultrasonics).

Owing to past selection there is considerable variation between breeds. At the same age and following the same plane of nutrition, cattle of the Charolaise or Blonde Aquitaine breeds, originally developed for draught purposes, or the Friesian, developed for milk production, give much leaner carcasses than do the Hereford or Aberdeen Angus which were originally selected as beef producers with an enhanced proportion of fat.

The opportunities are therefore available for replacing fat breeds by lean ones and for genetic selection to reduce the rate of fat deposition in fat breeds.

\section{Direct hormonal change}

Genetic selection presumably has its effect by changing the balance of the endocrine system and there are ways of effecting such a change by more direct action. Anabolic steroids may be used as feed additives or, rather more safely and conveniently, implanted subcutaneously in the form of slow-release tablets. The objective varies with the species; in cockerels, high doses of oestrogens, such as hexoestrol, are used chemically to castrate and encourage some fat deposition; in bullocks, wethers and hogs (all castrates), hexoestrol is used to stimulate nitrogen retention and therefore lean development. In females, the androgenic hormone, trenbolone acetate, may be used with the same objective. There is now some legal control over the use of steroids in this manner but the practice is widespread. There are many problems involved:

Although instructions to farmers regarding the use of hormones may be clear, it is difficult to enforce them; testing of meat for hormone residues, even where suitable methods are available, can only be done on a sample basis; when meat is exported, the importing country may have different regulations from those of the country of production. This subject was extensively reviewed at an FAO/WHO Symposium (FAO, 1975).

Castration is normally a routine practice with all farm mammals. It tends to quieten the temperament, essential in the days when animals were not slaughtered until long after sexual maturity. It also prevents the development of taints in the flesh which are particularly common in the boar and buck. However, castration also tends to encourage fat deposition.

With the earlier ages of slaughter, made possible by selection for faster growth, and also with the development of practical methods of animal separation and control, the need for castration is disappearing. Although there has been some consumer resistance to bull beef and boar pork, both are becoming acceptable and they are significantly leaner than their castrate equivalents.

In response to consumer demand, all of these

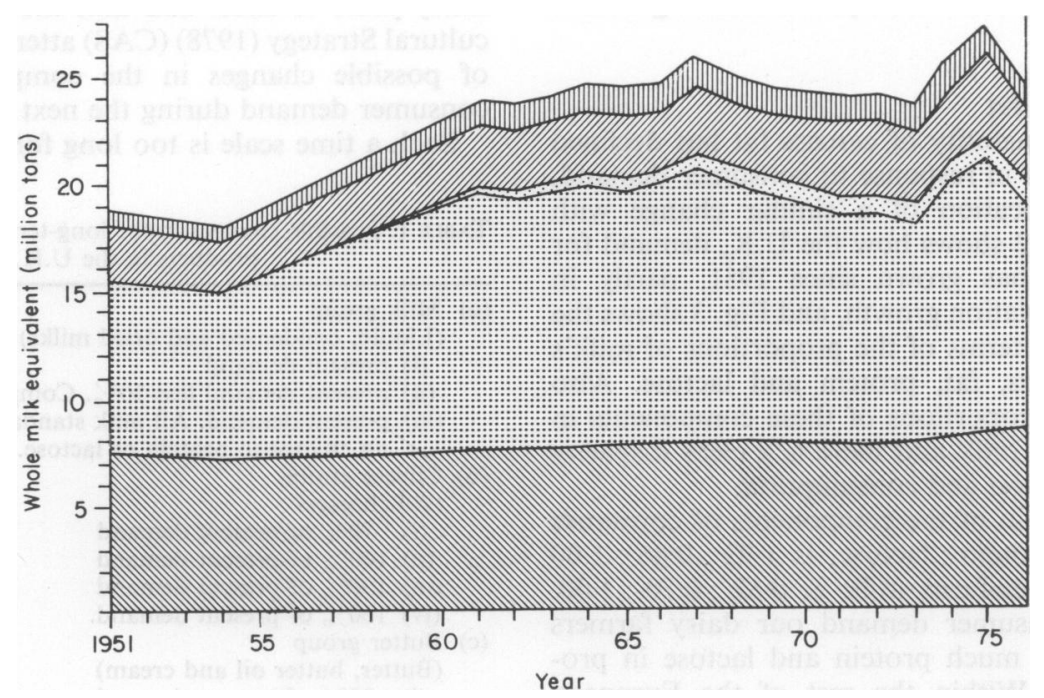

FIG. 2. The whole milk equivalent of the U.K. consumption of dairy products (1951-1976). $\mathbb{N}$ Liquid milk, butter, 圈 cream, $\mathbb{G}$ cheese, 血 other. 


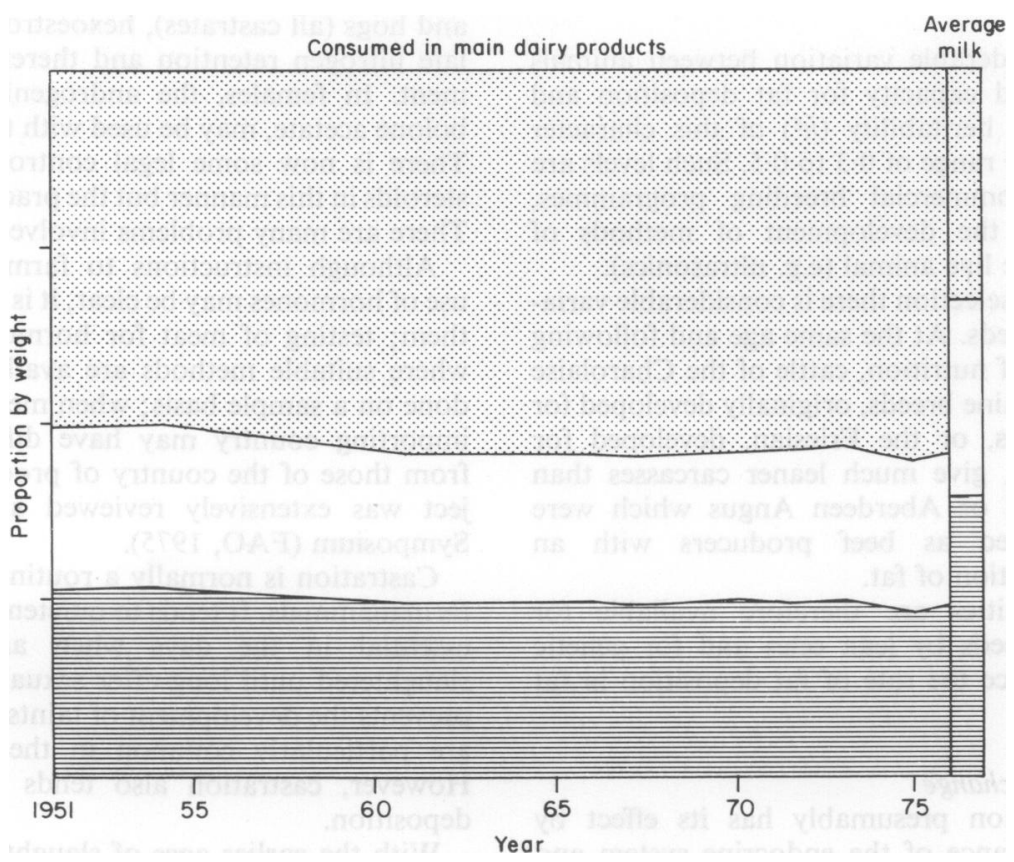

FIG. 3. The proportions of milk fat, protein, and lactose consumed in the main dairy products in the U.K. (1951-1976). 图 Fat, $\square$ protein, 目 lactose.

methods of reducing carcass fat have been, and are being, used. Already, the broiler chicken is nearly fat-free; many strains of pigs are said to be as lean as the consumer requires; much progress has been made with cattle, largely by breed substitution, and only the sheep breeders have yet to make significant changes.

\section{Quantity of milk fat}

Whereas the quantity of carcass fat has declined over recent years in response to consumer demand, there is no indication of a similar change with milk fat. Figure 2 shows how the U.K. demand for dairy products has grown since 1951, partly in response to population growth, and Fig. 3 shows the same demand in terms of the proportions of milk's main components, fat, protein and lactose. Also shown are the proportions of these components in average, ex-farm milk and there is a clear disparity between production and consumption.

The weight ratio of the components of consumer demand, fat : protein : lactose, is $1.92: 0.86: 1.00$ whilst that for ex-farm milk is $0.82: 0.70: 1.00$. For present consumer demand our dairy farmers produce far too much protein and lactose in proportion to fat. Within the rest of the European Community (EC) the disparity is even greater and disposal of the resultant surplus of skimmed milk costs $>£ 100 /$ dairy cow for each of the EC's 25 million cows.

As the market stands today, there is a clear demand for farmers to produce less milk but with a much higher proportion of fat. Such a change would take many years to effect and thus the Centre for Agricultural Strategy (1978) (CAS) attempted an estimate of possible changes in the components of U.K. consumer demand during the next 20-30 years.

Such a time scale is too long for extrapolation of

TABle 1. Possible changes in the long-term demand for dairy products in the U.K.

(a) Milk group

(Liquid, condensed and dried milks)

(i) present demand

(ii) present demand less $20 \%$. Composition unchanged.

(iii) present demand. All milk standardized to $2.5 \%$ fat; no change to protein or lactose.

(b) Cheese group

(All cheeses)

(i) $70 \%$ of present demand

(ii) $100 \%$ of present demand

(iii) $130 \%$ of present demand

(iv) $160 \%$ of present demand.

(c) Butter group

(Butter, butter oil and cream)

(i) $20 \%$ of present demand

(ii) $60 \%$ of present demand

(iii) $100 \%$ of present demand. 


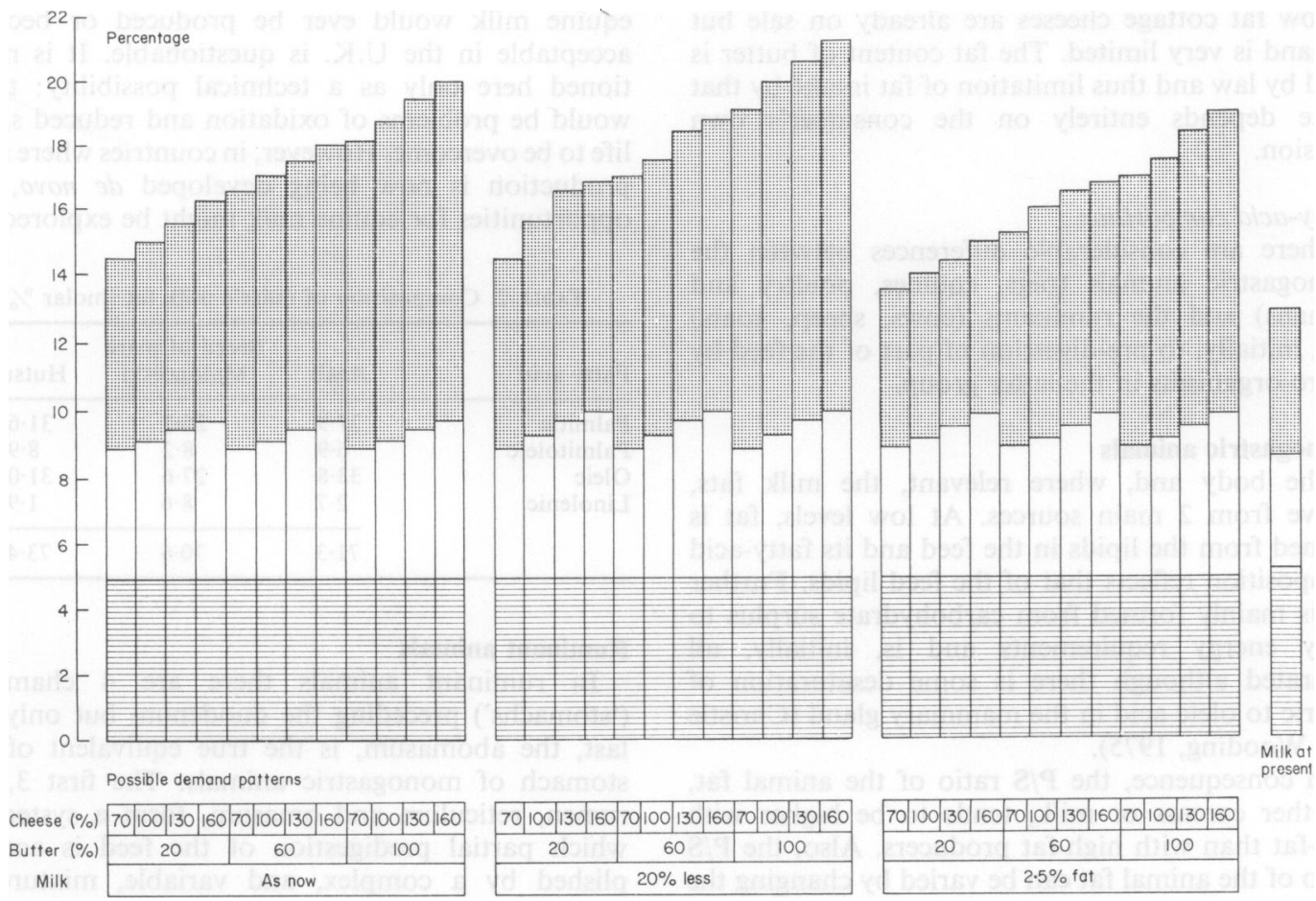

FIG. 4. Milk components required for different patterns of dairy product demand in the U.K. 图 Fat, $\square$ protein, 是 lactose.

current trends in demand and thus the problem was approached by considering a range of alternatives and then looking for common factors. All dairy products were classified into 3 groups and a range of possible changes postulated for each group as shown in Table 1. In all, 36 possible combinations of consumption were postulated and the fat : protein : lactose ratios of each were calculated. They are shown diagrammatically in Fig. 4.

The lowest level of fat consumption suggested goes well beyond present medical recommendation but, even then, the component ratio of $0.86: 0.80$ : 1.00 is still not as low in fat as present average farm milk. A fall in milk fat demand to such a level seems highly improbable to the CAS. The indications all point to a future consumption-component ratio with significantly more fat than that of present milk.

The CAS recommendation is that farmers should seek to produce a milk whose main components are in balance with market demand and that those components should then be apportioned to the various milk products according to the required compositions. This would include production of such low-fat liquid milks as the medical profession encouraged consumers to demand. The recommendation derives from a balanced consideration of all aspects of supply and demand and it should be clearly understood that there is no suggestion that consumers should drink milk with a higher fat content or consume a greater total amount of milk fat.

\section{Possible present action}

In so far as dairy products for direct human consumption are concerned, there would not appear to be any technical reasons why semi-skimmed milks should not be made available in the U.K. now. Other EC countries already provide them and their composition is defined by Community Directive $1411 / 71$.

Nor is it likely that difficulties would be encounered in accustoming consumers to drink such milks. Anyone who now omits to shake the milk bottle before decanting will be used to the high fat cream layer at the top and the low fat liquid below.

The problems of providing semi-skimmed (or skimmed) milk are largely economic. The cost and trouble involved in producing and retailing small quantities are not justified by the increase in price which consumers would be willing to pay. At present it is cheaper to buy whole milk and discard the cream. 
Low fat cottage cheeses are already on sale but demand is very limited. The fat content of butter is fixed by law and thus limitation of fat intake by that route depends entirely on the consumer's own decision.

\section{Fatty-acid composition}

There are considerable differences between the monogastric animals (pigs, equines, poultry and humans) and the ruminants (cows, sheep, goats) due, initially, to pre-digestion of part of the feed by micro-organisms in the latter group.

\section{Monogastric animals}

The body and, where relevant, the milk fats, derive from 2 main sources. At low levels, fat is formed from the lipids in the feed and its fatty-acid composition reflects that of the feed lipids. Further fat is mainly formed from carbohydrate surplus to daily energy requirements and is, initially, all saturated although there is some desaturation of stearic to oleic acid in the mammary gland (Christie and Wooding, 1975).

In consequence, the $\mathrm{P} / \mathrm{S}$ ratio of the animal fat, whether carcass or milk, tends to be higher with low-fat than with high-fat producers. Also, the P/S ratio of the animal fat can be varied by changing the quantity and composition of the lipids in the feed and the degree of this effect will be inversely related to the rate of fat formation.

Poultry fat has a high $\mathrm{P} / \mathrm{S}$ ratio simply because there is so little of it in the carcass. However, should it become economic to increase the energy value of a ration by adding a largely saturated oil, such as palm oil or coconut oil, then the feed $P / S$ ratio and consequently the poultry fat $\mathrm{P} / \mathrm{S}$ ratio would be lowered. This probably would not affect the P/S ratio of the average human diet, however, as the total quantity of poultry fat consumed is so small.

With pigs, the rapid reduction of carcass fat has probably increased the $\mathrm{P} / \mathrm{S}$ ratio slightly and will have a greater effect in future. This is already noticeable in the softness of the fat on very lean carcasses, particularly of boars. Since this symposium is concerned to increase proportions of unsaturated fats, it is worth noting that such change would not be favoured in the trade at present. Consumers are said not to favour oily fat on meat and unsaturated fats are subject to oxidative rancidity which reduces shelf-life. The current commercial pressure is therefore towards, rather than against, saturated fat on carcasses.

No milk from monogastric animals is produced for commercial sale in the U.K. at present but some equine milk is produced in parts of eastern Europe and Asia. Kulisa (1977) provides the data on maremilk fatty acids shown in Table 2 . As to whether equine milk would ever be produced or become acceptable in the U.K. is questionable. It is mentioned here only as a technical possibility: there would be problems of oxidation and reduced shelflife to be overcome. However, in countries where milk production is now being developed de novo, the opportunities for equine milk might be explored.

TABLE 2. Composition of mare's milk fat (molar $\%$ )

\begin{tabular}{lccc}
\hline Fatty acid & Arab & $\begin{array}{c}\text { Breed of mare } \\
\text { Malopolski }\end{array}$ & Hutsul \\
\hline Palmitic & 27.9 & 26.2 & 31.6 \\
Palmitoleic & 6.9 & 8.2 & 8.9 \\
Oleic & 33.8 & 27.6 & 31.0 \\
Linolenic & 2.7 & 8.6 & 1.9 \\
& 71.3 & 70.6 & 73.4 \\
\hline
\end{tabular}

\section{Ruminant animals}

In ruminant animals there are 4 chambers ('stomachs') preceding the duodenum but only the last, the abomasum, is the true equivalent of the stomach of monogastric animals. The first 3 , the rumen, reticulum and omasum, form a system in which partial predigestion of the feed is accome plished by a complex, and variable, mixture of micro-organisms. In effect, the rumen is a fermentas tion vat and the residue passing to the abomasumi for digestion by the animal's own enzymes is a mixture of micro-organisms, their metabolites and original feed which has escaped digestion.

The system is too complex for description here but a fuller account is given by Brumby and Welch (1978). For present purposes, the important consequence is that a high proportion of the unsaturated lipids in the feed is saturated by the micro-organisms. Thus, in comparison with monogastric animals, the $\mathbf{P} / \mathbf{S}$ ratio of both carcass and milk fats is lower.

With ruminants in the wild, a proportion of the feed is in the form of grass and other seeds which escape pre-digestion in the rumen but are digested in the abomasum and beyond. Thus much of the unsaturated feed lipid escapes saturation. Pastures for domesticated ruminants in developed countries are not usually allowed to reach the seeding stage as yields of digestible nutrients are thereby lowered and production costs increased. Even where seeds (such as cereal grains) are included in the diet, they are crushed before feeding, so opening the way for digestion and fatty-acid saturation in the rumen.

Methods of protecting oils against rumen digestion have recently been developed and consequent milk and dairy products, with an enhanced $\mathbf{P} / \mathbf{S}$ ratio, $\stackrel{?}{+}$ have been marketed in Australia in limited quantities. Reduced to its essentials, however, this is no more than an expensive way of evading legal constraints. 
Vegetable oil processed through the cow becomes milk fat which is entitled to such descriptions as 'dairy product' and 'butter'. The same oil mixed with milk fat makes such descriptions illegal. The most efficient way of increasing the $\mathbf{P}: \mathbf{S}$ ratio of butter is to change the law, not the method of feeding cows.

There is some suggestion (Edwards, King and Yousef, 1973) that the fatty-acid composition of cow's milk might be modified by genetic selection as heritability estimates are high (Table 3). These estimates were obtained from a study of the milk from monozygous and dizygous twins but the rather lower heritability estimates to be expected from

TABLE 3. The major fatty acids of cow's milk fat

\begin{tabular}{|c|c|c|c|}
\hline Fatty acid & Molar $\%$ & $\begin{array}{c}\text { Genetic } \\
\text { variance }\end{array}$ & Heritability \\
\hline $\mathrm{C} 4$ & $9 \cdot 9$ & 0.0604 & 0.82 \\
\hline C6 & $4 \cdot 4$ & 0.0588 & 0.88 \\
\hline $\mathrm{C} 8$ & $2 \cdot 0$ & 0.0586 & 0.87 \\
\hline $\mathrm{C} 10$ & $3 \cdot 2$ & $0 \cdot 1938$ & 0.88 \\
\hline $\mathrm{C} 12$ & 3.9 & 0.0676 & 0.64 \\
\hline $\mathrm{C} 14$ & $11 \cdot 1$ & $1 \cdot 7378$ & 0.89 \\
\hline $\mathrm{C} 15$ & $1 \cdot 2$ & 0.0104 & $0 \cdot 86$ \\
\hline C16 & $21 \cdot 6$ & $3 \cdot 5806$ & 0.95 \\
\hline $\mathrm{C} 18$ & $8 \cdot 1$ & 1.6562 & 0.88 \\
\hline $\mathrm{C} 14 \Delta^{9}$ & $1 \cdot 7$ & $0 \cdot 1156$ & 0.98 \\
\hline$C 16 \Delta^{9}$ & $3 \cdot 0$ & 0.0534 & 0.92 \\
\hline $\left.\begin{array}{l}C 18 \Delta^{9} \\
C 18 \Delta^{9}, 12\end{array}\right\}$ & $27 \cdot 3$ & $2 \cdot 3016$ & $0 \cdot 89$ \\
\hline $\mathrm{C} 18^{\Delta^{9,12,15}}$ & $1 \cdot 2$ & 0.0168 & 0.72 \\
\hline
\end{tabular}

field studies may well offer reasonable opportunity for selective breeding.

However, the small genetic variances for individual fatty acids would make useful change a long-term undertaking. A better understanding of the physiological mechanisms and of the genetic correlations with other production factors seems desirable as a first step. If, for instance, it could be shown that selection for one or a group of fatty acids could effect all required change, without adversely affecting yields of milk components, then incorporation in a breeding programme would seem practicable.

\section{References}

BRUMBY, P.E. \& WELCH, V.A. (1978) Lipid precursors of milk fatty acids. In: Biennial Reviews, 1978, National Institute for Research in Dairying, Reading.

Centre for Agricultural Strategy (1978) Strategy for the U.K. Dairy Industry. Centre for Agricultural Strategy, Reading.

Christie, W.W. \& Wooding, F.B.P. (1975) The site of triglyceride biosynthesis in milk. Experientia, 31, 1445.

EDWARDS, R.A., KING, J.W.B. \& YouSEF, I.M. (1973) A note on the genetic variation in the fatty acid composition of cow milk. Animal Production, 16, 307.

FoOD AND AgRICULture ORganization (1975) Report of the FAO/WHO Symposium on the Use of Anabolic Agents in Animal Production and its Public Health Aspects. Food and Agriculture Organization of the United Nations, Rome.

KulisA, M. (1977) Zwartość Niektórych wolnych aminokwasów oraz kwasów tluszczowych w mleku klaczy Arabskich Malopolskich i Huculskich. Rocziniki Naukowe Zootechniki, 4 (2), 79. 